\title{
LOW CONTROL AND HIGH DEMANDS AT WORK AS RISK FACTORS FOR SUICIDE: AN AUSTRALIAN NATIONAL POPULATION-LEVEL CASE-CONTROL STUDY
}

\section{Running title: Job Stressors and suicide}

\section{Milner A(PhD) ${ }^{12}$, Spittal MJ(PhD $)^{3}$, Pirkis J(PhD) ${ }^{3}$, Chastang J-F(PhD $)^{45}$, Niedhammer $\mathrm{I}(\mathrm{PhD})^{45}$, LaMontagne $\mathrm{AD}(\mathrm{ScD})^{12}$.}

${ }^{1}$ Work, Health, \& Wellbeing Unit, Centre for Population Health Research, School of Health \& Social Development, Deakin University, Geelong, Victoria, 3125

AUSTRALIA

${ }^{2}$ Centre for Health Equity, Melbourne School of Population and Global Health, University of Melbourne, Melbourne, Victoria 3010 AUSTRALIA

${ }^{3}$ Centre for Mental Health, Melbourne School of Population and Global Health, The University of Melbourne, Melbourne, Victoria 3010 AUSTRALIA

${ }^{4}$ INSERM, UMR_S 1136, Pierre Louis Institute of Epidemiology and Public Health, Department of social epidemiology, F-75013, Paris, FRANCE

${ }^{5}$ Sorbonne Universités, UPMC Univ Paris 06, UMR_S 1136, Pierre Louis Institute of Epidemiology and Public Health, Department of social epidemiology, F-75013, Paris, FRANCE

Corresponding author

Dr Allison Milner

Work, Health \& Wellbeing Unit, Centre for Population Health Research, Building BC3.213, School of Health \& Social Development _ D eak in U n iversity, Melbourne, VIC 3125 AUSTRALIA

Allison.milner@deakin.edu.au

Tel (intl) +61-3-9244-6802; Fax (intl) +61-03-9244-6624

Word count: 4959, Tables: 3

Conflicts of Interest and Source of Funding: No conflicts of interest. The research is support by the American Foundation for Suicide Prevention and Deakin University awarded to Allison Milner. 


\section{ABSTRACT}

Objectives: Previous research suggests that psychosocial job stressors may be plausible risk factors for suicide. This study assessed the relationship between psychosocial job stressors and suicide mortality across the Australian population.

Methods: We developed a Job Exposure Matrix to objectively measure job stressors across the working population. Suicide data came from a nation-wide coronial register. Living controls were selected from a nationally-representative cohort study. Incidence density sampling was used to ensure that controls were sampled at the time of death of each case. The period of observation for both cases and controls was 2001 to 2012. We used -multilevel logistic regression to assess the odds of suicide in relation to two psychosocial job stressors (job control and job demands), after matching for age, sex and year of death/survey and adjusting for SES.

Results: Across 9,010 cases and 14,007 matched controls, our results suggest that low job control (OR 1.35, 95\% CI 1.26 to 1.44, $\mathrm{p}<0.001$ ) and high job demands (OR 1.36, 95\% 1.26 to $1.46, \mathrm{p}<0.001$ ) were associated with increased odds of male suicide after adjusting for SES. High demands were associated with lower odds of female suicide (OR 0.81, 95\% CI 0.72 to $0.92, \mathrm{p}=0.002$ ).

Conclusions: It appears that adverse experiences at work are a risk factor for male suicide, while not being associated with an elevated risk among females. Future studies on job stressors and suicide are needed, both to further understand the biobehavioral mechanisms explaining the link between job stress and suicide, and also to inform targeted prevention initiatives.

Key words: suicide, job stress, occupation, case-control, work, employment, intentional self-harm. 
Abbreviations: JEM= Job-exposure matrices; NCIS= National Coroners Information System; ANZSCO= Australian and New Zealand Standard Classification of

Occupations; HILDA=Household, Income and Labour Dynamics in Australia study; OR= odds ratios; SES= socio-economic status; ICD-ten ; International Classification of Disease-version 10; SEIFA= Socio-Economic Indexes for Areas. 
Psychosocial job stressors represent aspects of work design, organisation or context that may cause psychological or physical harm. Some of the most commonly studied psychosocial job stressors are those expressed in the demand-control model[1]. Job demand refers most commonly to psychological demands associated with job tasks, but can also refer to physical, emotional or other specific types of demands. Job control describes an equally-weighted measure of decision authority at work (the level of decision-making authority over the way work is done) and skill discretion (the breadth of skills used on the job)[2].

There have been a number of studies demonstrating the adverse effects of exposure to chronic job stressors (including low control and high demands) on mental health [36]. Fewer have examined the relationship between psychosocial job stressors and suicide [7-12]. The few studies that have been done in this area have been confined to specific samples [9] or occupational cohorts [7, 10, 12]; there has been no populationlevel research on the relationship between psychosocial job stressors and suicide. One barrier to research in this area is the lack of systematically available exposure information on chronic psychosocial job stressors (such as low job control, high psychological demands, etc.,) in death records (e.g., documents included as part of a coroners inquest into deaths by suicide). Instead, coronial files typically contain information on proximal and acute life stressors easily discernable by investigating police officers as being risk factors for suicide, such as mental disorders and interpersonal conflict. Where information on job stressors is available, it may be subject to reporting bias as information is ascertained from subjective recollections of witnesses and those close to the deceased whose views may be influenced by knowledge of the suicide outcome. 
Methods for ascertaining reliable retrospective accounts of work-related exposures have been a long-standing area of interest to occupational epidemiologists[13]. Jobexposure matrices (JEMs) represent one method to improve the objectivity of job stressor exposure measurement[14]. As suggested by their name, JEMs comprise a matrix in which each intersection between rows (job titles) and columns (exposures) provides one or more estimates of exposure, such as prevalence, frequency or duration of this exposure within each job title. JEMs are particularly valuable when data are available on health outcomes and occupation within a population, but there is no information on exposure to job stressors[15], such as in coronial files. JEMs are recognised to be particularly useful when combined with validation studies to assess the precision of exposure estimates[16]. There have been a number of JEMs developed to estimate exposure to psychosocial job stressors internationally, but none to date in Australia[17-23].

In order to enable the investigation of job stressor exposures and their relationship with suicide outcomes at the population level, we have previously developed a JEM specifically designed to assess psychosocial job stressors in the Australian context using a nationally-representative, longitudinal panel study that has been running since 2001[24]. In this study, we use this JEM to conduct a population-level case-control study, estimating job stressor exposures for suicide cases and controls based on occupation. This extends previous research because while a number of studies have used JEM-estimated measures of job stressors in studies with mental health outcomes[25-27], none have assessed the relationship with a hard endpoint such as suicide mortality. 


\section{METHOD}

Data source for cases

Suicide cases over the period 2001 to 2012 were sourced from the National Coroners Information System (NCIS) and coded by occupation by two researchers (independently). Occupational information was coded according to the Australian and New Zealand Standard Classification of Occupations (ANZSCO) to the four-digit level[28]. More information on the coding of suicide cases by occupation can be seen in previous published material[29].

Data source for controls:

Controls were a random sample of living subjects obtained from the Household, Income and Labour Dynamics in Australia (HILDA) Survey[24]. HILDA is a nationally-representative, longitudinal panel study of Australian residents aged 15 years and over[24]. Survey data have been collected annually since 2001, gathering information on a variety of factors, including demographic, social, economic, work and health measures using a combination of face-to-face interviews and a selfcompletion questionnaire. The response rate to wave 1 was 66\%[24]. From 2002 onwards, the retention rates for the HILDA survey have been above $90 \%$ for respondents who have continued in the survey. The response rates for new respondents being invited into the study is above $70 \%[24]$.

The HILDA cohort was chosen as a source of controls because it represented the primary base population from where the cases originated. The importance of sampling from the primary base has been emphasized by several researchers[30, 31] as this provides an indication of the distribution of the exposures (e.g., psychosocial job 
stressors) in the general population. Further, the time period for which data on the controls was available matched the period of observation of the cases. To be eligible for inclusion in case-control analysis, controls had to be employed and have available occupational data at the 4-digit level.

\section{Outcome}

The outcome was death from suicide, as coded using the International Classificaiton of Disease (ICD-Ten) (X60-X84).

\section{Exposure}

\section{Development of the JEM}

The JEM used in this study is described in more detail elsewhere[32]. Briefly, it was developed using the HILDA cohort ( $n=20,428$ employed people) for four common psychosocial job stressors: job control, job demands and complexity, job insecurity, and fairness of pay. These continuous measures have been characterised psychometrically and shown to be prospectively related to mental and physical health outcomes in previous research [33-35].

Because job stressor exposures pattern differently by sex as well as by occupation[36], our JEM was constructed separately for males and females. This was done using self-reported measures of the four psychosocial job stressors. First, population medians (across all occupations) were generated for each stressor by pooling all contributed waves by sex; these later served as cut-points for dichotomising into high and low exposures. To construct the JEM, summary 
measures were derived by sex and ANZSCO 4-digit occupation (358 titles in ANZSCO), as follows:

1) Generating the mean of job stressors for all waves contributed by an individual study participant (using means allowed us to adjust these using the weights available in HILDA to ensure the estimates were representative of the Australian working population) by each occupational title they held;

2) Pooling these individual-level means to generate a mean stressor exposure level for each ANZSCO 4-digit occupation. Occupation-level estimates were only generated if there were 10 or more persons in an ANZSCO 4-digit occupation. This resulted in approximately $10 \%$ of occupations being excluded from the JEM, and;

3) Exposure estimates by occupation were dichotomised into high and low using the cut-point defined by population medians described above. E.g., Low control, high demands, high job insecurity, and low fairness of pay.

This process for developing the JEM followed similar methods established in previous studies [17, 23].

\section{Validation of the JEM}

As in previous JEM studies [17, 23], we assessed concordance between the JEMassigned and individually-reported exposures using the Kappa statistic, sensitivity and specificity assessments. We retained those exposures that had a good kappa agreement (above 0.60) between individual- and JEM-assigned reports (job demands and control). We did not use our measures of job security and fairness of pay, which had a kappa agreement with individual reports around 0.50 and were thus deemed as too low. Specificity was highest for job control and demands, with values of 0.70 or 
more (measuring the extent to which the JEM correctly classified those non-exposed) and relatively lower for fairness of pay and job security. For both males and females, job control and job demands had the highest sensitivity (over 0.50), which measures the extent to which the JEM assigned exposures correctly identified people who reported being exposed (i.e. to low job control or to high demands). For more information on JEM development and validation, please see [32].

\section{Statistical analysis}

To avoid including data from the same control more than once in the analyses, we randomly selected data from each control only once using the incidence density risk set sampling matching method utilised in a previous case-control study with a similar JEM approach[26]. Incidence density sampling ensures that controls are sampled at the time of death of each case. In the case of this study, where we used a longitudinal cohort as the control population, this allowed us to match controls to cases by selecting controls who were surveyed in the year that their case died. For example, a case that died in 2001 would be matched with a control interviewed in 2001. Next, 4digit occupation codes for cases and controls were used to extract corresponding job demand and control exposure estimates from the JEM (as binary exposures). We also matched cases to controls by age group (15 to 34 years, 35 to 54 years, 55 years and over) and sex. While we initially aimed to select multiple controls, in practice there were approximately 1.55 controls per case (see Table 1). This means for some cases (e.g., females, where there were a smaller total number of suicides) we were able to match a larger number of controls (e.g., 2 controls), while for others (e.g., males) the matching procedure may have only been able to assign one control for each case. 
We initially compared the overall level of exposure to binary measures of job stressors in cases versus controls using descriptive analysis (e.g., proportion exposed, frequencies of cases versus control exposed with chi-square tests). Following this, we used a multilevel logistic regression to assess the odds of exposure to high job demands and low job control in cases (expressed as an odds ratio [OR]) versus controls. Both stressors were included the same model. This allowed us to model both fixed and random effects simultaneously. The random effects accounted for correlation within each matched cases and control (e.g., age, sex, year of death/survey), while the fixed effects represented the between-persons effects between cases and controls. As a sensitivity analysis, we conducted a multilevel logistic regression with continuous job stressor variables.

We tested that the relationship between job stressors and suicide differed by sex by including an interaction term in regression models. Significance was assessed by examining the overall model against a main effects model using the likelihood-ratio test.

The model adjusted for socio-economic status (SES) using the Socio-Economic Indexes for Areas (SEIFA, published by the Australian Bureau of Statistics[37]), which ranks areas in Australia according to relative socio-economic advantage and disadvantage. The indexes are based on information from the five-yearly Census, and a low SEIFA value indicates lower social and human capital in an area[37]. As a sensitivity test, we also adjusted for occupational skill level using the eight major groupings (1 digit level occupation grouping) of the Australian and New Zealand Standard Classification of Occupations (ANZSCO)[28], although we acknowledge 
that this may be seen as overadjustment by some (as JEM exposures are imputed via occupation).

\section{RESULTS}

The characteristics of the sample included in the case-control analysis can be seen in Table 1 . The majority of the sample was male, reflecting the greater number of males who died by suicide in Australia in the study period compared to females (there were also a greater number of male controls). In total, $63.7 \%$ of cases were exposed to low job control compared to $59.7 \%$ of controls, and $75.6 \%$ of cases were exposed to high job demands compared to $71 \%$ of controls. As a group, cases were slightly older than controls and had slightly lower SES. Cases were also more likely to be employed as technical or trades workers or machinery operators or drivers but less likely to be employed as professionals, in clerical and administrative jobs or as sales workers

-- please insert Table 1 ---

There was a significant interaction between job control and sex (males*low job control = OR 1.47, 95\% CI 1.25 to $1.73, \mathrm{p}<0.001$ ) as well as between psychological demands and sex (males*high psychological demands = OR 1.87, 95\% CI 1.58 to 2.21, $\mathrm{p}<0.001$ ) in relation to suicide outcomes. We therefore report all results stratified by sex.

For females, there was no difference in the odds of exposure to low control in cases versus controls, independent of SES and after matching. Female cases had lower odds 
of being exposed to high demands than controls (OR 0.81, 95\% 0.72 to 0.92, $\mathrm{p}=0.002$ ). For males, cases had higher odds of exposure to low control (OR 1.35, 95\% CI 1.26 to 1.44, $\mathrm{p}<0.001$ ) and high demands (OR 1.36, 95\% CI 1.26 to $1.46, \mathrm{p}<0.001$ ) than controls.

-- please insert Table 2 ---

The sensitivity analysis adjusting for ANZSCO occupational level can be seen in Table 3. For females, there was no significant difference in the relationship between psychosocial job stressors between cases and controls after adjusting for occupational skill and socio-economic status. In contrast, male cases had higher odds than controls of being exposed to low job control (OR 1.24, 95\% CI 1.14 to 1.34 , $\mathrm{p}<0.001$ ) and high psychological demands (OR 1.33 , 95\% CI 1.23 to $1.45, \mathrm{p}<0.001$ ) than male controls. The second sensitivity analysis using continuous job stressor variables (note: coded the opposite way for job control, whereby higher scores represented higher job control; higher scores on the demands variable represented higher demands) revealed null effects for job control (Males OR 1.00, 95\% CI 0.98 to $1.02, p=0.938$; Females OR 1.00, 95\% CI 0.97 to 1.03 , p=0.956). Higher scores of psychological demands (e.g., higher demands) were associated with higher odds of suicide for males (OR 1.10, 95\% CI 1.07 to 1.14, $\mathbf{p}<\mathbf{0 . 0 0 1}$ ), and lower odds of suicide for women (OR 0.96, 95\% CI 0.94 to 0.97 , $\mathbf{p}<\mathbf{0 . 0 0 1 )}$.

\section{DISCUSSION}


We used a population-level case control study to assess exposure to job stressors in suicide cases versus living controls. Our data source for cases represented all available data on suicide in the Australian population, while the control population comprised of a population representative and matched sample. Given this, and the fact that suicide is a relatively "rare" outcome, the odds ratios calculated in this study are interpreted as an approximation of the relative risk in the general population. Thus, the study results suggest that psychosocial job stressors are significant risk factors for male suicide, but associated with lower risk of suicide for women in the Australian population. In a sensitivity analysis adjusting for occupational skill level and SES, the observed association for women dropped out of significance, but was maintained for men. Further, our power to detect associations was far larger in males that females due to a greater number of suicides in the former.

Our results align with previous studies on the relationship between psychosocial job stressors and suicide. A psychological autopsy (interviews with next-of-kin of those who have died by suicide) case-control study in Germany showed that monotonous work (an element of job control) and excessive feelings of responsibility at work (job demands) were risk factors for suicide [9]. A cohort study in Japan [7] reported 4point greater relative-risk of death from suicide among employed males with low job control compared with a male control group, while job demands were not associated with risk of death from suicide. There has also been some research into psychosocial working conditions and risk of suicide in specific industries such as nurses and sawmill workers[10, 12]. For female nurses in the US, high exposure to work-family conflict was associated with a greater relative risk of suicide deaths [12], while job mobility, and low psychological demands were associated with increased odds of 
suicide death in male mill-workers [10]. The study on mill-workers also found that low social support was a risk factor for attempted suicide [10]. This research broadly aligns with a large body of research regarding the effects of low control and high demands on the development of depression [3]. While little is known about possible psychobiological mechanisms, it is possible that chronic stress alters the hypothalamic-pituitary adrenocortical axis, leading to higher risk of depression [3], and possibly suicide.

As noted earlier, these previous studies were conducted in specific occupational contexts or samples and were based on a low number of observed suicides. Our study advances this research as it used an objective measure of psychosocial job stressors, as calculated using a JEM designed specifically for the same context that the suicide data is drawn from. Further, because we were able to conduct analysis over the entire working population our results are generalizable across all occupations. Some of the benefits of using JEMs include that fact they reduce bias that might be present in individual self-report records, and lead to little or no bias in terms of effect estimates (although we acknowledge they will be associated with a loss of precision and lower power than studies that use individual level data)[16]. JEM approaches are particularly valuable when researchers have health outcome data, but no reliable measure of exposure, such as in the case of suicide data. The JEM we developed performed adequately when assessed against individual self-report for job demands and control, but relatively poorly for job insecurity and fairness of pay. This suggests that alternate means of assessing exposure to job insecurity and fairness of pay need to be developed. However, we would note that our results are similar to the individual 
reported studies on suicide and work factors discussed in the paragraph above[7, 9, $10,12]$.

There were some marked sex differences that are worth comment. For females, we found that controls were more likely to be exposed to high demands than cases. However, this result dropped out of significance in sensitivity analysis adjusting for occupational skill level. Potentially, this suggests that occupational skill level (e.g., whether a female was working in a low versus higher skilled job) has stronger influence on suicide than job stressors. In stating this, it is important to acknowledge that the job stressors examined in this study (job control and demands) are likely to pattern by skill level, thus including skill level may in fact represent an over adjustment. We would also knowledge that the results for females may be related to the fact that we did not have measure of pressures outside the workplace (e.g., at home), which may also contribute to female experiences of stress (as in a study on nurses[12], which found the greatest risk of suicide was apparent when females had the combination of stress at home and at work). Notwithstanding this, we would suggest further investigation is needed into whether higher job demands may actually be protective against female suicide. For example, whether higher job demands brings about feelings of job satisfaction and overall fulfilment for females.

Our results for males suggest that adverse psychosocial factors at work are, on average, risk factors for male suicide. This finding extends previous research, which has suggested males - more than females - are particularly vulnerable to problems related to the inability to effectively fulfil the "breadwinner" role traditionally considered as central to hegemonic masculinity[38]. Past research has also indicated 
that males appear to have substantially elevated suicide rates in low-skill jobs that have traditionally been characterised as having poor psychosocial job quality[29, 39, 40].

The limitations of this paper include the fact that we were only able to reliably measure two psychosocial job stressors (control and demands), and were therefore not able to assess many other factors within the workplace that may contribute to suicide risk, such as bullying [41, 42]. Another limitation is that we were not able to control for history of mental disorder. However, we would argue that including this in statistical models is likely to represent over-adjustment, as mental illness is also likely to be a mediating factor on the pathway between adverse work factors and suicide[43]. We must also acknowledge problems related to the under-reporting of suicide in the National Coroners Information System, as in any official record of death. Occupation may also have been misreported in police reports or miscoded by our research team, which may have occurred in the use of a structured approach to classification.

Another factor that should be considered is that measurement provided by a JEM will lack precision compared to individual level accounts but are associated with lower likelihood of bias - as they are more likely to represent the "average” experience of job stress across a given occupation[16]. We would have also liked the opportunity to validate the JEM using an independent sample group. At the time of this study, we had no comparable data source with information on both males and females that could be used for this purpose. The major strengths of our study include the use of the best available individual-level data on suicide and coverage across an entire national 
population over a twelve-year period. We would suggest that these strengths outweigh the study's limitations.

In conclusion, our study suggests that low control and high demands at work are associated with increased suicide among males, but not females. This suggests that need for workplace directed prevention initiatives that specifically target males and take their working conditions into account. In Australia, the employed population is estimated to comprise of 6.4 million men and 5.5 million women [44]. Addressing adverse work environments among this large proportion of the population has the potential to have large preventative effects for mental health problems [45]. There is growing appreciation that such approaches are also needed in the field of suicide prevention.[46] We would also recommend that future studies are conducted, both to further understand the relationship between adverse factors at work and suicide, and also to inform targeted prevention initiatives. 


\section{ACKNOWLEDGEMENTS}

This paper uses unit record data from the Household, Income and Labour Dynamics in Australia HILDA Survey. The HILDA Project was initiated and is funded by the Australian Government Department of Social Services DSS and is managed by the Melbourne Institute of Applied Economic and Social Research Melbourne Institute. The findings and views reported in this paper, however, are those of the authors and should not be attributed to either DSS or the Melbourne Institute. The data used in this paper was extracted using the Add-On Package PanelWhiz for Stata. PanelWhiz (http://www.PanelWhiz.eu) was written by Dr. John P. Haisken-DeNew (john@PanelWhiz.eu).

\section{AUTHOR CONTRIBTIONS}

AM conceived the article. IN, JFC, MS, JP and ADL contributed to the design of the analysis and paper. MS provided advice on interpretation of results. All authors contributed to drafts and the final manuscript.

\section{FUNDING INFORMATION}

This work was supported by the American Foundation for Suicide Prevention and Deakin University. 


\section{REFERENCES}

1. Karasek R, Brisson C, Kawakami N, Houtman I, Bongers P, Amick B: The Job Content Questionnaire (JCQ): an instrument for internationally comparative assessments of psychosocial job characteristics. J Occup Health Psychol 1998, 3(4):322-355.

2. Karasek RA, Theorell T: Healthy work: stress, productivity and the reconstruction of working life. New York: Basic Books; 1990.

3. Siegrist J: Chronic psychosocial stress at work and risk of depression: evidence from prospective studies. Eur Arch Psychiatry Clin Neurosci 2008, 258:115-119.

4. Stansfeld S, Candy B: Psychosocial work environment and mental health--a meta-analytic review. Scand J Work Environ Health 2006, 32(6):443-462.

5. Nieuwenhuijsen K, Bruinvels D, Frings-Dresen M: Psychosocial work environment and stress-related disorders, a systematic review. Occup Med 2010, 60(4):277-286.

6. Bonde JPE: Psychosocial factors at work and risk of depression: a systematic review of the epidemiological evidence. J Occup Environ Med 2008, 65(7):438-445.

7. Tsutsumi A, Kayaba K, Ojima T, Ishikawa S, Kawakami N, Jichi Med School Cohort Study Grp: Low control at work and the risk of suicide in Japanese men: A prospective cohort study. Psychother Psychosom 2007, 76(3):177-185

8. Takada M, Suzuki A, Shima S, Inoue K, Kazukawa S, Hojoh M: Associations between Lifestyle Factors, Working Environment, Depressive Symptoms and Suicidal Ideation: A Large-scale Study in Japan. Ind Health. 2009, 47(6):649-655

9. Schneider B, Grebner K, Schnabel A, Hampel H, Georgi K, Seidler A: Impact of employment status and work-related factors on risk of completed suicide. A case-control psychological autopsy study. Psychiatry Res 2011, 190(2-3):265-270.

10. Ostry A, Maggi S, Tansey J, Dunn J, Hershler R, Chen L, Louie AM, Hertzman C: The impact of psychosocial work conditions on attempted and completed suicide among western Canadian sawmill workers. Scand J Public Health 2007, 35(3):265-271.

11. Inoue K, Nishimura Y, Nishida A, Fukunaga T, Masaki M, Fujita Y, Nata M, Okazaki $Y$, Ono $Y$ : Relationships between suicide and three economic factors in South Korea. Leg Med, 12(2):100-101.

12. Feskanich D, Hastrup JL, Marshall JR, Colditz GA, Stampfer MJ, Willett WC, Kawachi I: Stress and suicide in the Nurses' Health Study. J Epidemiol Community Health 2002, 56(2):95-98.

13. Nieuwenhuijsen M: Introduction to exposure assessment. In: Exposure Assessment in Occupational and Environmental Epidemiology. Edited by Nieuwenhuijsen M: Oxford Scholarship Online; 2009.

14. Teschke K: Exposure surrogates: job-exposure matrices, self-reports, and expert evaluations. In: Exposure Assessment in Occupational and Environmental Epidemiology. edn. Edited by Nieuwenhuijsen M: Oxford Scholarship Online; 2009. 
15. Niedhammer I, Chastang J-F, Levy D, David S, Degioanni S, Theorell T: Study of the validity of a job-exposure matrix for psychosocial work factors: results from the national French SUMER survey. Int Arch Occup Environ Health 2008, 82(1):87-97.

16. Armstrong B: Exposure measurement error: consequences and design issues. In: Exposure Assessment in Occupational and Environmental Epidemiology. Edited by Nieuwenhuijsen M: Oxford Scholarship Online; 2009.

17. Solovieva S, Pensola T, Kausto J, Shiri R, Heliövaara M, Burdorf A, Husgafvel-Pursiainen K, Viikari-Juntura E: Evaluation of the Validity of Job Exposure Matrix for Psychosocial Factors at Work. PLOS ONE 2014, 9(9):e108987.

18. Schwartz JE, Pieper CF, Karasek RA: A procedure for linking psychosocial job characteristics data to health surveys. Am J Public Health 1988, 78(8):904-909.

19. Johnson JV, Stewart WF: Measuring work organization exposure over the life course with a job-exposure matrix. Scand J Work Environ Health 1993, 19(1):21-28.

20. Kauppinen T, Toikkanen J, Pukkala E: From cross-tabulations to multipurpose exposure information systems: a new job-exposure matrix. Am J Ind Med 1998, 33(4):409-417.

21. Rijs KJ, van der Pas S, Geuskens GA, Cozijnsen R, Koppes LLJ, van der Beek AJ, Deeg DJH: Development and Validation of a Physical and Psychosocial Job-Exposure Matrix in Older and Retired Workers. Ann Occup Hyg 2013.

22. Wieclaw J, Agerbo E, Bo Mortensen P, Burr H, Tuchsen F, Bonde JP: Psychosocial working conditions and the risk of depression and anxiety disorders in the Danish workforce. BMC Public Health 2008, 8:280.

23. Niedhammer I, Chastang JF, Levy D, David S, Degioanni S, Theorell T: Study of the validity of a job-exposure matrix for psychosocial work factors: results from the national French SUMER survey. Int Arch Occup Environ Health 2008, 82(1):87-97.

24. Wilkins R: Families, Incomes and Jobs, Volume 8: A Statistical Report on Waves 1 to 10 of the Household, Income and Labour Dynamics in Australia Survey. . Melbourne: Melbourne Institute of Applied Economic and Social Research Faculty of Business and Economics; 2013.

25. Seidler A, Nienhaus A, Bernhardt T, Kauppinen T, Elo AL, Frolich L: Psychosocial work factors and dementia. Occup Environ Med 2004, 61(12):962-971.

26. Wieclaw J, Agerbo E, Mortensen PB, Burr H, Tuchsen F, Bonde JP: Psychosocial working conditions and the risk of depression and anxiety disorders in the Danish workforce. BMC Public Health 2008, 8:280.

27. Cohidon C, Santin G, Chastang JF, Imbernon E, Niedhammer I: Psychosocial exposures at work and mental health: potential utility of a job-exposure matrix. J Occup Environ Med 2012, 54(2):184-191.

28. ABS: Australian and New Zealand Standard Classification of Occupations, 2013, Version 1.2 . Cat. No. 1220.0 Canberra: ABS; 2013. 
29. Milner AJ, Niven H, LaMontagne AD: Occupational class differences in suicide: evidence of changes over time and during the global financial crisis in Australia. BMC Psychiatry 2015, 15:223.

30. Rothman KJ, Greenland S, Lash TL: Chapter 8: Case-Control Studies. In: Modern Epidemiology, 3rd Edition. edn. Philadelphia: Wolters Kluwer Health/Lippincott Williams \& Wilkins; 2008.

31. Wachoider S, Silverman DT, McLaughlin JK, Mandel JS: Selection of Controls in Case-Control Studies. Am J Epidemiol 1992, 135:1042-1050.

32. Milner A, Niedhammer I, Chastang J-F, Spittal MJ, LaMontagne AD: Validity of a Job-Exposure Matrix for psychosocial job stressors: Results from the Household Income and Labour Dynamics in Australia Survey. PLOS One. http://dx.doi.org/10.1371/journal.pone.0152980.

33. Butterworth P, Leach LS, Rodgers B: Psychosocial job adversity and health in Australia: analysis of data from the HILDA Survey. Aust $N Z \mathrm{~J}$ Public Health 2011, 35(6):564-571.

34. Butterworth P, Leach LS, Strazdins L, Olesen SC, Rodgers B, Broom DH: The psychosocial quality of work determines whether employment has benefits for mental health: results from a longitudinal national household panel survey. Occup Environ Med 2011, 68(11):806-812.

35. Leach L, Rodgers B, Butterworth P, Strazdins L: Deriving an evidencebased measure of job quality from the HILDA survey. Australian Social Policy 2010, 9:67-86.

36. LaMontagne AD, Krnjacki L, Kavanagh AM, Bentley R: Psychosocial working conditions in a representative sample of working Australians 2001-2008: an analysis of changes in inequalities over time. Occ Environ Med 2013, 70(9):639-647.

37. ABS: Socio-Economic Indexes for Areas. Accessed from http://www.abs.gov.au/websitedbs/censushome.nsf/home/seifa on the 16 Jan 2016: Australia Bureau of Statistics; 2016.

38. Payne S, Swami V, Stanistreet DL: The social construction of gender and its influence on suicide: a review of the literature. J Mens Health 2008, 5(1):23-35.

39. Milner AJ, Spittal MS, Pirkis J, LaMontagne AD: Does Gender Explain the Relationship Between Occupation and Suicide? Findings from a Meta-Analytic Study. Community Ment Health J 2015.

40. Milner A, Spittal MJ, Pirkis J, LaMontagne AD: Suicide by Occupation: A systematic review and meta-analysis. $B r J$ Psychiatry 2013, 203:409416.

41. Nielsen MB, Nielsen GH, Notelaers G, Einarsen S: Workplace Bullying and Suicidal Ideation: A 3-Wave Longitudinal Norwegian Study. $\mathrm{Am} \mathrm{J}$ Public Health 2015:e1-e6.

42. Milner A, Page K, Witt K, LaMontagne AD: Psychosocial working conditions and suicide ideation: evidence from a cross-sectional survey of working Australians. J Occup Environ Med in press.

43. Milner A, Page A, LaMontagne AD: Cause and effect in studies of unemployment, mental health, and suicide: a meta-analytic and conceptual review. Psychol Med 2013, 44(5):909-919. 
44. ABS: Labour Force, Australia, May 2016. Catalogue number 6202.0. Canberra: Australian Bureau of Statistics.

45. LaMongtagne AD, Martin A, Page KM, Reavley NJ, Noblet A, Milner A, Keegel T, Smith P: Workplace mental health: Developing an integrated intervention approach. BMC Psychiatry 2014, 14(131): doi:10.1186/1471-1244X-1114-1131.

46. Milner A, Page K, Spencer-Thomas S, Lamotagne AD: Workplace suicide prevention: a systematic review of published and unpublished activities. Health Promot Int 2014, doi: 10.1093/heapro/dau085. 
Table 1. Sample description of cases and controls

\begin{tabular}{l|l|l}
\hline & $\begin{array}{l}\text { Cases } \\
(\mathbf{n = 9 , 0 1 0 )}\end{array}$ & $\begin{array}{l}\text { Controls } \\
(\mathbf{n = 1 4 , 0 0 7 )}\end{array}$ \\
\hline Male \% & 84.1 & 67.0 \\
Female \% & 16.0 & 33.0 \\
\hline Low job control \% & 63.7 & 59.7 \\
High job demands \% & 75.6 & 71.0 \\
\hline 15-34 yrs \% & 36.4 & 49.2 \\
35 - 54 yrs \% & 50.9 & 40.1 \\
55 yrs and over \% & 12.7 & 10.7 \\
\hline SES - lowest \% & 22.5 & 26.5 \\
SES - 2nd \% & 31.0 & 20.7 \\
SES - 3rd \% & 24.7 & 25.4 \\
SES - highest \% & 21.8 & 27.4 \\
\hline Managers & 12.3 & 12.1 \\
Professionals & 13.9 & 18.6 \\
Technicians and trades & 21.3 & 14.7 \\
Community and personal service & 9.6 & 9.8 \\
Clerical and administrative & 6.6 & 11.4 \\
Sales workers & 6.0 & 11.2 \\
Machinery operators and drivers & 11.3 & 7.0 \\
Labourers & 18.9 & 06.2 \\
\hline Notes: SES measured using & & 9.9 \\
\hline
\end{tabular}

Notes: SES measured using the SEIFA index; the eight occupational groups measured using ANZSCO. 
Table 2. Multilevel mixed-effects logistic regression, odds ratio of suicide in relation to exposure to job demands and job control.

\begin{tabular}{lllllll}
\hline Females & Case & Controls & OR & Low & Upp & p value \\
& & & & CI & CI & \\
\hline Low control & 659 & 2,308 & 0.91 & 0.80 & 1.02 & 0.166 \\
High control & 784 & 2,309 & 1 & & & \\
\hline High demands & 808 & 2,911 & 0.81 & 0.72 & 0.92 & 0.002 \\
Low demands & 635 & 1,706 & 1 & & & \\
\hline Males & & & & & & \\
\hline & Case & Controls & OR & Low & Upp & p value \\
& & & & CI & CI & \\
\hline Low control & 5,084 & 3342 & 1.35 & 1.26 & 1.44 & $<0.001$ \\
High control & 2,483 & 6,048 & 1 & & & \\
\hline High demands & 6,006 & 7,032 & 1.36 & 1.26 & 1.46 & $<0.001$ \\
Low demands & 1,561 & 2,358 & 1 & & & \\
\hline
\end{tabular}

Notes: OR= odds ratio; Upper CI= Upp 95\% Confidence Intervals; Low CI= Lower 95\% Confidence Intervals. Incidence density sampling was used to ensure that controls are sampled at the time of death of each case. Cases and controls matched by age and sex. Models control for age and SES. 
Table 3. Multilevel mixed-effects logistic regression, odds ratio of suicide in relation to exposure to job demands and job control, adjusting occupational skill level.

\begin{tabular}{lllllll}
\hline Females & & & & & & \\
& Case & Controls & OR & Low & Upp & p value \\
& & & & CI & CI & \\
\hline Low control & 659 & 2308 & 0.94 & 0.83 & 1.07 & 0.373 \\
High control & 784 & 2,309 & 1 & & & \\
\hline High demands & 808 & 2,911 & 0.83 & 0.71 & 1.09 & 0.353 \\
Low demands & 635 & 1,706 & 1 & & & \\
\hline Males & & & & & & \\
\hline & Case & Controls & OR & Low & Upp & p value \\
& & & & CI & CI & \\
\hline Low control & 5,084 & 3342 & 1.24 & 1.14 & 1.34 & $<0.001$ \\
High control & 2,483 & 6,048 & 1 & & & \\
\hline High demands & 6,006 & 7,032 & 1.33 & 1.23 & 1.45 & $<0.001$ \\
Low demands & 1,561 & 2,358 & 1 & & &
\end{tabular}

Notes: OR= odds ratio; Upper CI= Upp 95\% Confidence Intervals; Low CI= Lower 95\% Confidence Intervals. Incidence density sampling was used to ensure that controls are sampled at the time of death of each case. Cases and controls matched by age and sex. Models control for occupational skill level (ANZSCO), age and SES. 


\section{University Library}

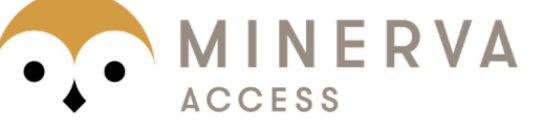

A gateway to Melbourne's research publications

Minerva Access is the Institutional Repository of The University of Melbourne

\section{Author/s:}

Milner, A;Spittal, MJ;Pirkis, J;Chastang, J-F;Niedhammer, I;LaMontagne, AD

Title:

Low Control and High Demands at Work as Risk Factors for Suicide: An Australian National Population-Level Case-Control Study

\section{Date:}

2017-04-01

\section{Citation:}

Milner, A., Spittal, M. J., Pirkis, J., Chastang, J. -F., Niedhammer, I. \& LaMontagne, A. D. (2017). Low Control and High Demands at Work as Risk Factors for Suicide: An Australian National Population-Level Case-Control Study. PSYCHOSOMATIC MEDICINE, 79 (3), pp.358-364. https://doi.org/10.1097/PSY.0000000000000389.

Persistent Link:

http://hdl.handle.net/11343/123538 